\title{
IMPLEMENTASI MEDIA PEMBELAJARAN EDUKATIF UNTUK POS PAUD TERPADU (PPT) DI KELURAHAN BALAS KLUMPRIK KECAMATAN WIYUNG KOTA SURABAYA
}

\author{
Nur Fathonah ${ }^{1}$, Erlin Ladyawati ${ }^{2}$ \\ ${ }^{1,2}$ Fakultas Keguruan dan Ilmu Pendidikan, Universitas PGRI Adi Buana Surabaya \\ email : nurunipa@gmail.com ${ }^{1}$,erlin.evaluasi@gmail.com ${ }^{2}$
}

\begin{abstract}
Abstrak
Anak usia dini berada pada masa emas (golden age). Karena itu, rangsangan lingkungan yang sehat dan sesuai, melalui kegiatan yang sesuai dengan tahap perkembangan anak, harus diberdayakan. Rangsangan dan kegiatan tersebut diharapkan akan berpengaruh pada pertumbuhan berbagai aspek, seperti fisik motorik, kognitif, sosial emosional, termasuk aspek bahasa. Salah satu metode pembelajaran yang dapat dijadikan alternatif solusi untuk masalah tersebut yaitu metode permainan. Metode permainan dalam hal ini adalah metode yang menggunakan permainan untuk mengemas suatu pembelajaran agar pembelajaran menjadi menyenangkan. Agar pembelajaran dengan menggunakan permainan lebih menarik maka diperlukan media. Media yang digunakan selain menyenangkan juga yang edukatif, atau yang memberi pengetahuan. Media pembelajaran edukatif dapat digunakan untuk memberikan rangsangan pada anak usia dini sehingga dapat meminimalkan hambatan yang mungkin terjadi ketika anak memperoleh atau menerima materi. Media pembelajaran edukatif dapat digunakan sebagai alternatif karena dapat dirancang sesuai dengan usia dan tingkat perkembangan anak, mudah digunakan oleh para murid PAUD, orang tua juga bunda PAUD, serta menyenangkan. Subyek dalam kegiatan ini adalah Bunda-bunda di Pos Paud Terpadu (PPT) RW 01 (PPT Bougenville) dan RW 06 (PPT Dahlia). Sedangkan luaran yang ingin dicapai adalah media pembelajaran edukatif. Metode yang digunakan ada dua yaitu metode proyek dan metode penilaian. Metode proyek digunakan untuk membuat media pembelajaran. Media pembelajaran yang dibuat ada dua jenis yaitu media pembelajaran jenis aktif dan media pembelajaran jenis pasif. Media pembelajaran jenis aktif yang dihasilkan adalah Balok Ceria dan Panggung Cerita, sedangkan media pembelajaran jenis pasif adalah Bantal Cerita Bergambar dan Tablet Permainan. Dari media pembelajaran yang dihasilkan akan diadakan penilaian terhadap ketepatan penggunaan kepada peserta didik melalui metode penilaian. Media pembelajaran layak digunakan jika memenuhi kriteria $\geq 80 \%$, dan semua media pembelajaran yang dihasilkan memenuhi kriteria tersebut. Dengan adanya kegiatan ini maka diharapkan bunda-bunda PAUD menjadi bunda-bunda yang berkualitas untuk mencerdaskan anak bangsa di barisan terdepan.
\end{abstract}

Kata Kunci : Kelompok Bunda PAUD, Media Pembelajaran Edukatif Jenis Aktif dan Media Pembelajaran Edukatif Jenis Pasif

\section{A. PENDAHULUAN}

Belum adanya media pembelajaran edukatif yang memadai menjadi salah satu penyebab anak cepat bosan untuk mengikuti arahan belajar dari bunda PAUD. Anak usia dini berada pada masa emas (golden age). Karena itu, rangsangan lingkungan yang sehat dan sesuai, melalui kegiatan yang sesuai dengan tahap perkembangan anak, harus diberdayakan. Rangsangan dan kegiatan tersebut diharapkan akan berpengaruh pada pertumbuhan berbagai aspek, seperti fisik motorik, kognitif, sosial emosional, termasuk aspek bahasa.

Salah satu metode pembelajaran yang dapat dijadikan alternatif solusi untuk masalah tersebut yaitu metode permainan. Metode permainan dalam hal ini adalah metode yang menggunakan permainan untuk mengemas suatu pembelajaran agar pembelajaran menjadi menyenangkan. Agar pembelajaran dengan menggunakan 
permainan lebih menarik maka diperlukan media. Media yang digunakan selain menyenangkan juga yang edukatif, atau yang memberi pengetahuan. Media pembelajaran edukatif dapat digunakan untuk memberikan rangsangan pada anak usia dini sehingga dapat meminimalkan hambatan yang mungkin terjadi ketika anak memperoleh atau menerima materi.

Media pembelajaran edukatif dapat digunakan sebagai alternatif karena dapat dirancang sesuai dengan usia dan tingkat perkembangan anak, mudah digunakan oleh para murid PAUD, orang tua juga bunda PAUD, serta menyenangkan. Selain itu, media pembelajaran edukatif merupakan kegiatan yang memungkinkan terjadinya interaksi bahasa dan simbol sehingga memfasilitasi anak untuk memperoleh pengetahuan yang luas dengan cara yang menyenangkan. Melalui Media pembelajaran edukatif diharapkan anak usia dini lebih banyak mendapat contoh kosa kata berikut maknanya sehingga apabila nantinya berkomunikasi dapat memahami dan memproduksi suatu kosa kata secara tepat. Tidak bisa dipungkiri lagi dengan pesatnya perkembangan jaman dan teknologi yang semakin canggih, anak-anak usia dini pun bisa mengoperasikan peralatan canggih seperti Laptop, Ipad, Iphone, Tab dan lain sebagainya. Tentunya dengan kondisi seperti ini banyak orang tua yang khawatir akan perkembangan psikis dan kecerdasan mereka yang salah arah. Hal itu tidak hanya menjadi tanggung jawab para orang tua saja karena para murid PAUD lebih banyak menghabiskan waktu luan mereka di rumah, tetapi para bunda PAUD juga merasa bertanggung jawab atas perkembangan psikis dan emosional mereka. Hal yang dapat dilakukan oleh para Bunda PAUD adalah mengolah peralatan canggih agar isi dari peralatan canggih tersebut harus bersifat edukatif.

Dari paparan diatas, maka impian PAUD yang akan datang diantaranya adalah:

a. Pembelajaran Berpusat Kepada Anak;

Media pembelajaran yang berpusat kepada anak (salah satunya adalah menggunakan media pembelajaran edukatif)

b. Kualifikasi Guru/tenaga Kependidikan;
Guru yang dibutuhkan anak didiknya adalah yang sesuai dengan kualifikasi yang ditetapkan dalam Peraturan Menteri 58 tahun 2009 tentang Standar Paud. yang menyangkut Latar Belakang Pendidikan, Kompetensi Kepribadian, dan Kompetensi Sosial.

c. Peran Forum Paud;

Peran Forum Paud pada saat ini masih sangat vital yaitu utamanya dalam upaya terus mensosialisasikan program paud hingga di tingkat lapangan. Sedangkan pada masa yang akan datang masih diperlukan utamanya dalam mengembangkan Paud yang holistickomprehensif, penelitian dan pengembangan, serta sebagai wadah para ahli di berbagai disiplin ilmu yang terkait program paud.

Untuk menggapai impian itu, kiranya diperlukan beberapa prasyarat yang harus dipenuhi, selain alokasi anggaran yang ideal, mengoptimalkan tenaga Kependidikan dan juga pelatihan tenaga pendidik perlu dilanjutkan yang setidaknya meliputi (1) Pelatihan Dasar, dan (2) Pelatihan Lanjutan. Pelatihan-pelatihan tersebut sangat penting dan mendesak agar kemampuan Tenaga Pendidik serta pemahamannya tentang Tumbuh-Kembang Anak terus berkembang, dengan mengacu peraturan pemerintah tentang Standar Paud. (Isnanto, Totok, 2011).

Berdasarkan permasalahan tersebut, pembahasan diarahkan pada (1) pendidikan anak usia dini, (2) pemerolehan kosa kata, (3) media pembelajaran edukatif, (4) keterkaitan media pembelajaran edukatif dengan perkembangan bahasa anak usia dini, dan (5) penerapan media pembelajaran edukatif dalam pembelajaran bahasa anak usia dini.

\section{B. SUBYEK PENELITIAN}

Subyek dalam kegiatan ini adalah bundabunda di PPT RW 01 yaitu PPT Bougenville dan bunda-bunda di PPT RW 06 yaitu PPT Dahlia.Lokasi kelurahan Balas Klumprik sekitar $14 \mathrm{~km}$ dari Universitas PGRI Adi Buana Surabaya. Di kelurahan Balas Klumprik ini sekitar 9 Rukun Warga (RW). Setiap RW mempunyai Pos PAUD Terpadu (PPT). PPT yang akan dijadikan subyek adalah PPT di RW 01, PPT di RW 06, dan PPT di RW 07. 
Pengetahuan dan pemahaman bunda di wilayah ini masih kurang terkait dengan desain pembelajaran ataupun inovasi kegiatan pembelajaran lainnya.

Tidak hanya di kota-kota besar, masalah rendahnya tingkat pemahaman anak usia dini/PAUD terhadap bahasa juga dialami oleh anak-anak yang ada di PPT Kelurahan Balas Klumprik Kecamatan Wiyung Kota Surabaya. Dari hasil wawancara langsung dengan ketua PPT Wilayah RW 06 yaitu Ibu Eka Sujandari H dan hasil survei di lapangan, media pembelajaran edukatif di PPT yang ada di wilayah Kelurahan Balas Klumprik Kecamatan Wiyung Kota Surabaya sangat kurang memadai.

Kurangnya media pembelajaran edukatif untuk anak dimungkinkan karena cepatnya perkembangan anak akan pengetahuan teknologi canggih yang kurang dipahami oleh bundabunda PPT seperti televisi, video online, internet dan lain-lain. Hal ini ini sangat berpengaruh terhadap tingkat kecerdasan anak karena kosakata dan peralatan canggih tidak seimbang.

\section{METODE PELAKSANAAN Tahap Pelaksanaan}

Ada tiga tahap dalam metode dalam kegiatan ini. Tiga tahap itu antara lain: tahap perencanaan, tahap pelaksanaan, dan tahap penilaian.

Pada tahap perencanaan, langkah kegiatan dilakukan yaitu merumuskan tujuan dan tema kegiatan, menganalisis karakteristik anak, merumuskan strategi pembelajaran, merancang kebutuhan sumber belajar, dan merancang media pembelajaran edukatif.

Pada tahap pelaksanaan atau tahap pengembangan, langkah kegiatan yang dilakukan adalah mempersiapkan bahan dan alat yang diperlukan untuk pembuatan media pembelajaran edukatif, mengadakan pelatihan membuat dan menggunakan media pembelajaran edukatif kepada bunda PAUD, dan penerapan penggunaan media pembelajaran edukatif kepada murid PAUD dengan pendampingan orang tua.

Sedangkan tahap penilaian dilakukan untuk mengetahui keberhasilan media pembelajaran edukatif yang telah dirancang, dibuat, dan diterapkan. Tanpa adanya kegiatan penilaian, guru/bunda PAUD/orang tua tidak dapat mengetahui ketercapaian tujuan pembelajaran setelah menggunakan media pembelajaran edukatif. Tujuan pembelajaran yang dimaksud yaitu pengharapan guru pada perolehan pengalaman belajar dari para siswa. Dengan mengetahui hal tersebut, dapat membuat keputusan keberhasilan kualitas pembelajaran.

\section{Alur Pelaksanaan}

Dalam kegiatan ini kegiatan awal yang dilakukan adalah analisis situasi tempat program Kegiatan akan diadakan. Lalu meminta ijin kepada ketua PPT di masing-masing RW. Setelah ijin dari ketua PPT di dapat maka ketua pelaksana program Kegiatan meminta ijin ke kepala desa Balas Klumprik, yaitu Ibu Sri Mudjiati, SH., MM. . Ijin dari beberapa pihak yang terkait sudah didapat maka ketua pelaksana bersama anggota menyusun proposal.

\section{HASIL DAN PEMBAHASAN}

\section{Hasil}

Berikut uraian kegiatan yang telah dilaksanakan.

1. Tahap perencanaan

Kegiatan yang telah dilaksanakan pada tahap perencanaan antara lain:

a. Merumuskan tujuan dan tema kegiatan Pada kegiatan ini, kami berdiskusi dengan beberapa ahli beserta tim dan ketua paguyuban Bunda PAUD se-Kelurahan Balas Klumprik melalui rapat koordinasi untuk merumuskan tujuan dan tema kegiatan yang akan dicapai.

b. Menganalisis karakteristik anak

Setelah tujuan dan tema berhasil dirumuskan maka kegiatan selanjutnya adalah berkunjung ke PAUD sasaran guna melihat karakteristik anak didk secara keseluruhan disertai wawancara dengan Bunda PAUD guna memvalidkan pengamatan.

c. Merumuskan strategi pembelajaran Kegiatan selanjutnya adalah merumuskan strategi pembelajaran yang bertujuan agar kami tidak salah pilih media sehingga tujuan media tepat sasaran pada usia anak didk.

d. Merancang kebutuhan sumber belajar 
Dari rancangan strategi harus disesuaikan dengan kebutuhan PAUD dan siswasiswanya.

e. Merancang media pembelajaran edukatif

Media dirancang guna memenuhi kebutuhan belar anak usia dini. Media yang dirancang anata lain:

1. Media pembelajaran Edukatif yang bersifat aktif : Balok Ceria dan Panggung cerita

2. Media pembelajaran Edukatif yang bersifat pasif : Bantal Cerita dan media Tablet (media berbasis IT)

2. Tahap pelaksanaan atau tahap pengembangan Kegiatan yang telah dilakukan pada tahap ini meliputi:

a. Kegiatan Sosialisasi

Kegiatan sosialisasi ini bertempat di PPT

Dahlia RW VI. Dengan mengusung tema

"Media Pembelajaran Edukatif untuk Anak Usia Dini" pada kegiatan sosialisasi ini, yang bertindak sebagai narasumber adalah Nur Fathonah, S.Pd., M.Pd. (narasumber 1), Erlin Ladyawati, S.Pd., M.Pd. (narasumber 2), Made Ayu Anggreni S.Pd., M.Pd. (narasumber 3). Pada kegiatan ini dipaparkan tentang pentingnya media pembelajaran untuk anak didik usia dini agar pembelajaran berlangsung dengan menyenangkan.

b. Kegiatan Workshop

Kegiatan workshop kali ini yaitu pelatihan membuat dan menggunakan media pembelajaran edukatif kepada bunda PAUD yang juga bertempat di PPT RW 06 atau PPT Dahlia.

Dari Pelaksanaan workshop tersebut dihasilkan duajenis media pembelajaran. Dua jenis media pembelajaran tersebut yang pertama adalah media pembelajaran jenis aktif dan media pembelajaran jenis pasif. Media pembelajaran jenis aktif adalah media pembelajaran yang mengaktifkan seluruh alat gerak. Media pembelajaran jenis aktif yang dihasilkan adalah balok ceria dan panggung cerita.
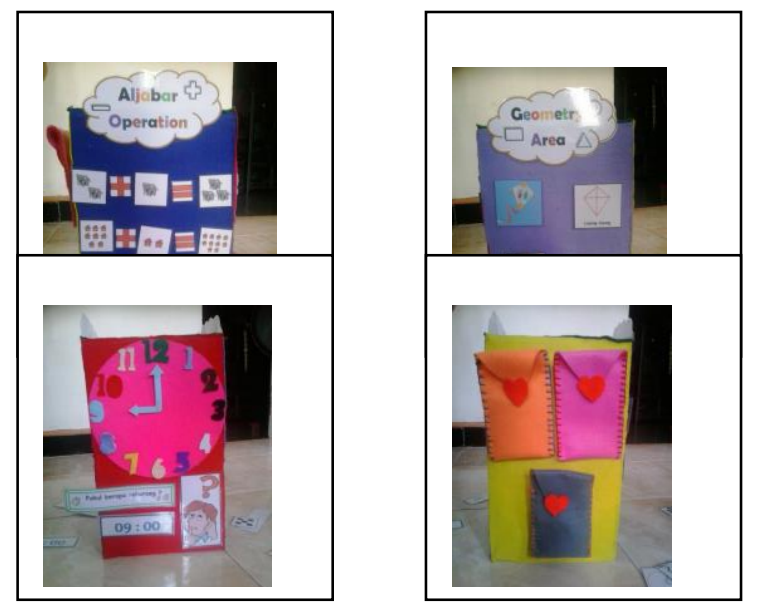

Gambar 1. Balok Ceria

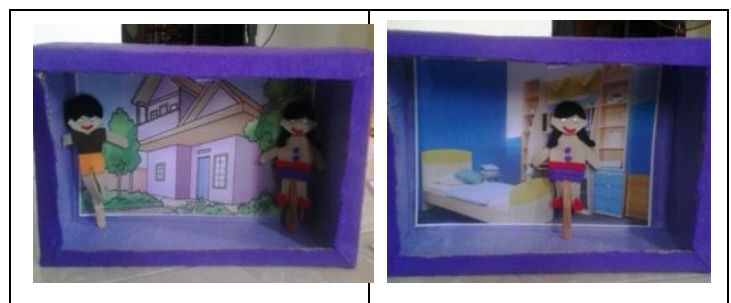

Gambar 2. Panggung Cerita

Media pembelajaran jenis pasif adalah media pembelajaran yang hanya mengaktifkan beberapa alat gerak. Media pembelajaran jenis pasif yang dihasilkan adalah bantal cerita bergambar dan tablet permainan. Berikut paparannya.

\section{BANTAL CERITA BERGAMBAR} (Untuk Usia 4-5 Tahun)

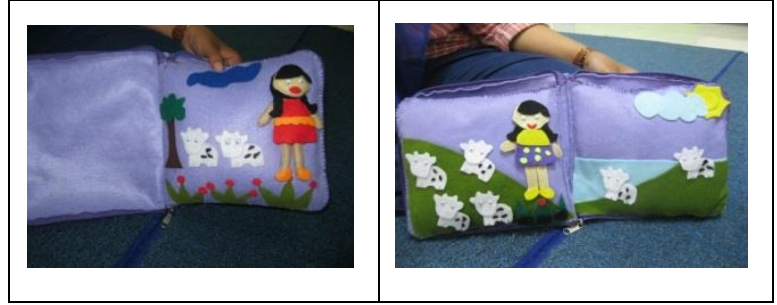

Gambar 3. Bantal Cerita Bergambar 


\section{TABLET PERMAINAN}

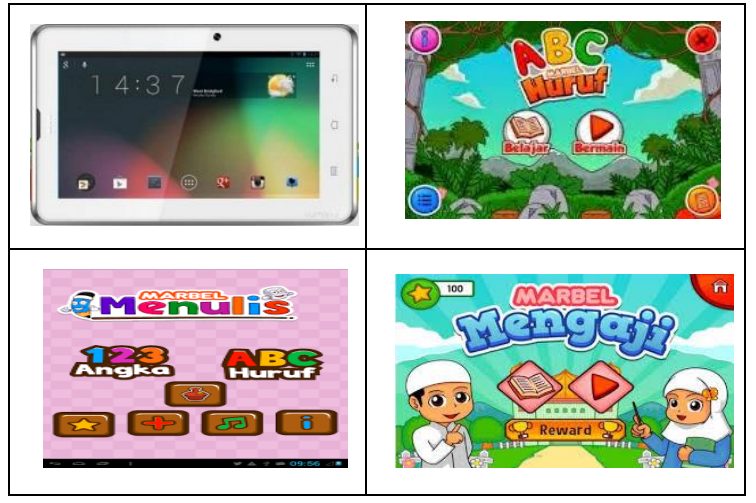

Gambar 4. Tablet Permainan

3. Kegiatan Pendampingan

Kegiatan pendampingan adalah kegiatan berkunjung ke Pos PAUD Terpadu untuk memantau pembelajaran secara langsung dan menilai fungsi media pembelajaran secara langsung

4. Tahap Penilaian

Pada kegiatan pendampingan dilakukan juga penilaian terhadap media pembelajaran. Media pembelajaran memberikan manfaat yang baik ketika kemampuan atau skill peserta didik dalam menggunakan media pembelajaran yang juga dikategorikan baik. Setiap media pembelajaran dikategorikan baik jika lebih dari sama dengan $80 \%(\geq 80 \%)$ peserta didik mampu atau tuntas dalam memenuhi indikator setiap permainan. Berikut kriteria penggunaan media pembelajaran.

Tabel 1. Daftar Kriteria Penggunaan Media Pembelajaran

\begin{tabular}{|c|l|c|}
\hline No & $\begin{array}{c}\text { Persentase } \\
\text { Rata-Rata }\end{array}$ & Kriteria \\
\hline 1 & $0 \% \leq \mathrm{x}<30 \%$ & $\begin{array}{c}\text { Tidak layak } \\
\text { digunakan }\end{array}$ \\
\hline 2 & $\begin{array}{l}30 \% \leq \mathrm{x}< \\
50 \%\end{array}$ & $\begin{array}{c}\text { Layak digunakan } \\
\text { dengan banyak } \\
\text { perubahan }\end{array}$ \\
\hline 3 & $\begin{array}{l}50 \% \leq \mathrm{x}< \\
80 \%\end{array}$ & $\begin{array}{c}\text { Layak digunakan } \\
\text { dengan sedikit } \\
\text { perubahan }\end{array}$ \\
\hline 4 & $\begin{array}{l}80 \% \leq \mathrm{x} \leq \\
100 \%\end{array}$ & $\begin{array}{c}\text { Layak digunakan } \\
\text { dengan baik }\end{array}$ \\
\hline
\end{tabular}

Berikut dijabarkan tentang perolehan persentase di kedua subyek yaitu PPT RW 01
(PPT Bougenvile) dan PPT RW 06 ( PPT Dahlia).

a. PPT RW 01 ( PPT Bougenvile)

1. Balok Ceria

Tabel 2. Daftar Persentase Kemampuan Siswa dalam Menggunakan Balok Ceria PPT Bougenvile

\begin{tabular}{|c|l|c|}
\hline No & Indikator & $\begin{array}{c}\text { Persentase } \\
\text { Kemampuan } \\
\text { Siswa }\end{array}$ \\
\hline 1 & $\begin{array}{l}\text { Menempel } \\
\text { angka sesuai } \\
\text { jarum jam dan } \\
\text { kegiatan yang } \\
\text { dilakukan }\end{array}$ & $90 \%$ \\
\hline 2 & $\begin{array}{l}\text { Mengetahui } \\
\text { persamaan di } \\
\text { benda di di } \\
\text { sekitar dengan } \\
\text { bentuk } \\
\text { geometri }\end{array}$ & $88 \%$ \\
\hline 3 & $\begin{array}{l}\text { Membilang 1 } \\
\text { sampai dengan } \\
10\end{array}$ \\
\hline Persentase Rata-rata & $88 \%$ \\
\hline
\end{tabular}

\section{Panggung Cerita}

Tabel 3. Daftar Persentase Kemampuan Siswa dalam Menggunakan Panggung Cerita PPT Bougenvile

\begin{tabular}{|c|l|c|}
\hline No & \multicolumn{1}{|c|}{ Indikator } & $\begin{array}{c}\text { Persentase } \\
\text { Kemampua } \\
\text { n Siswa }\end{array}$ \\
\hline 1 & $\begin{array}{l}\text { Mampu memainkan } \\
\text { peran (laki-laki dan } \\
\text { perempuan) }\end{array}$ & $92 \%$ \\
\hline 2 & $\begin{array}{l}\text { Mampu bercerita } \\
\text { sesuai background } \\
\text { yang disediakan }\end{array}$ & $89 \%$ \\
\hline 3 & $\begin{array}{l}\text { Mampu } \\
\text { berkomunikasi/ } \\
\text { berbahasa yang } \\
\text { baik dan benar }\end{array}$ & $85 \%$ \\
\hline 4 & $\begin{array}{l}\text { Berani tampil di } \\
\text { depan kelas }\end{array}$ & $85 \%$ \\
\hline \multicolumn{2}{|l|}{ Persentase Rata-rata } & $89 \%$ \\
\hline
\end{tabular}


3. Bantal Cerita Bergambar

Tabel 4. Daftar Persentase Kemampuan

Siswa dalam Menggunakan Bantal Cerita

Bergambar PPT Bougenvile

\begin{tabular}{|c|l|c|}
\hline No & Indikator & $\begin{array}{c}\text { Persentase } \\
\text { Kemampuan } \\
\text { Siswa }\end{array}$ \\
\hline 1 & $\begin{array}{l}\text { Mampu } \\
\text { bercerita } \\
\text { sesuai } \\
\text { gambar }\end{array}$ & $85 \%$ \\
\hline 2 & $\begin{array}{l}\text { Mampu } \\
\text { berbahasa } \\
\text { yang baik dan } \\
\text { benar }\end{array}$ & $85 \%$ \\
\hline 3 & $\begin{array}{l}\text { Berani tampil } \\
\text { di depan } \\
\text { kelas }\end{array}$ & $85 \%$ \\
\hline \multicolumn{2}{|c|}{ Persentase Rata- } \\
rata
\end{tabular}

4. Tablet Permainan

Tabel 5. Daftar Persentase

Kemampuan Siswa dalam

Menggunakan Tablet Permainan PPT

Bougenvile

\begin{tabular}{|c|l|c|}
\hline No & \multicolumn{1}{|c|}{ Indikator } & $\begin{array}{c}\text { Persentase } \\
\text { Kemampuan } \\
\text { Siswa }\end{array}$ \\
\hline 1 & $\begin{array}{l}\text { Mampu } \\
\text { mengoperasikan } \\
\text { tablet } \\
\text { (menyalakan dan } \\
\text { memilih } \\
\text { permainan) }\end{array}$ & $87 \%$ \\
\hline 2 & $\begin{array}{l}\text { Mampu fokus } \\
\text { pada permainan } \\
\text { yang dipilih }\end{array}$ & $86 \%$ \\
\hline 3 & $\begin{array}{l}\text { Mampu bermain } \\
\text { dengan } \\
\text { permainan } \\
\text { aplikasi yang } \\
\text { dipilih } \\
\text { (mengenal } \\
\text { angka, huruf, } \\
\text { gambar, warna, } \\
\text { dll) }\end{array}$ \\
\hline Persentase Rata-rata & $88 \%$ \\
\hline
\end{tabular}

b. PPT RW 06 ( PPT Dahlia )

1. Balok Ceria

Tabel 6. Daftar Persentase Kemampuan

Siswa dalam Menggunakan Balok Ceria PPT Dahlia

\begin{tabular}{|c|l|c|}
\hline No & Indikator & $\begin{array}{c}\text { Persentase } \\
\text { Kemampuan } \\
\text { Siswa }\end{array}$ \\
\hline 1 & $\begin{array}{l}\text { Menempel } \\
\text { angka sesuai } \\
\text { jarum jam dan } \\
\text { kegiatan yang } \\
\text { dilakukan }\end{array}$ & $86 \%$ \\
\hline 2 & $\begin{array}{l}\text { Mengetahui } \\
\text { persamaan } \\
\text { benda di } \\
\text { sekitar dengan } \\
\text { bentuk } \\
\text { geometri }\end{array}$ \\
\hline 3 & $\begin{array}{l}\text { Membilang 1 } \\
\text { sampai dengan } \\
10\end{array}$ \\
\hline Persentase Rata-rata & $87 \%$ \\
\hline
\end{tabular}

2. Panggung Cerita

Tabel 7. Daftar Persentase Kemampuan Siswa dalam Menggunakan Panggung Cerita PPT Dahlia

\begin{tabular}{|c|l|c|}
\hline No & \multicolumn{1}{|c|}{ Indikator } & $\begin{array}{c}\text { Persentase } \\
\text { Kemampu } \\
\text { an Siswa }\end{array}$ \\
\hline 1 & $\begin{array}{l}\text { Mampu } \\
\text { memainkan peran } \\
\text { (laki-laki dan } \\
\text { perempuan) }\end{array}$ & $90 \%$ \\
\hline 2 & $\begin{array}{l}\text { Mampu bercerita } \\
\text { sesuai background } \\
\text { yang disediakan }\end{array}$ & $88 \%$ \\
\hline 3 & $\begin{array}{l}\text { Mampu } \\
\text { berkomunikasi/ } \\
\text { berbahasa yang } \\
\text { baik dan benar }\end{array}$ & $85 \%$ \\
\hline 4 & $\begin{array}{l}\text { Berani tampil di } \\
\text { depan kelas }\end{array}$ & $84 \%$ \\
\hline \multicolumn{2}{|l}{ Persentase Rata-rata } & $87 \%$ \\
\hline
\end{tabular}


3. Bantal Cerita Bergambar

Tabel 8. Daftar Persentase Kemampuan Siswa dalam Menggunakan Bantal Cerita Bergambar PPT Dahlia

\begin{tabular}{|c|l|c|}
\hline No & \multicolumn{1}{|c|}{ Indikator } & $\begin{array}{c}\text { Persentase } \\
\text { Kemampu } \\
\text { an Siswa }\end{array}$ \\
\hline 1 & $\begin{array}{l}\text { Mampu } \\
\text { bercerita sesuai } \\
\text { gambar }\end{array}$ & $82 \%$ \\
\hline 2 & $\begin{array}{l}\text { Mampu } \\
\text { berbahasa yang } \\
\text { baik dan benar }\end{array}$ & $86 \%$ \\
\hline 3 & $\begin{array}{l}\text { Berani tampil di } \\
\text { depan kelas }\end{array}$ & $89 \%$ \\
\hline \multicolumn{2}{|l|}{ Persentase Rata-rata } & $86 \%$ \\
\hline
\end{tabular}

4. Tablet Permainan

Tabel 9. Daftar Persentase Kemampuan Siswa dalam Menggunakan Tablet Permainan PPT Dahlia

\begin{tabular}{|c|l|c|}
\hline No & \multicolumn{1}{|c|}{ Indikator } & $\begin{array}{c}\text { Persentase } \\
\text { Kemampuan } \\
\text { Siswa }\end{array}$ \\
\hline 1 & $\begin{array}{l}\text { Mampu } \\
\text { mengoperasikan } \\
\text { tablet } \\
\text { (menyalakan dan } \\
\text { memilih } \\
\text { permainan) }\end{array}$ & $87 \%$ \\
\hline 2 & $\begin{array}{l}\text { Mampu fokus } \\
\text { pada permainan } \\
\text { yang dipilih }\end{array}$ & $86 \%$ \\
\hline 3 & $\begin{array}{l}\text { Mampu bermain } \\
\text { dengan } \\
\text { permainan } \\
\text { aplikasi yang } \\
\text { dipilih } \\
\text { (mengenal } \\
\text { angka, huruf, } \\
\text { gambar, warna, } \\
\text { dll) }\end{array}$ \\
\hline Persentase Rata-rata & $85 \%$ \\
\hline
\end{tabular}

Dari hasil kedua subyek tersebut maka persentase rata-rata media pembelajaran sebagai berikut.
1. Balok Ceria

Tabel 10. Persentase Rata-Rata Balok Ceria

\begin{tabular}{|c|lll|c|}
\hline No & \multicolumn{3}{|c|}{ PPT } & Persentase \\
\hline 1 & $\begin{array}{l}\text { PPT RW 01 (PPT } \\
\text { Bougenville) }\end{array}$ & $88 \%$ \\
\hline 2 & $\begin{array}{l}\text { PPT RW 06 (PPT } \\
\text { Dahlia) }\end{array}$ & $87 \%$ \\
\hline \multicolumn{3}{|c|}{ Persentase Rata-rata } & $87,5 \%$ \\
\hline
\end{tabular}

2. Panggung Cerita

Tabel 11. Persentase Rata-Rata Panggung Cerita

\begin{tabular}{|c|lll|c|}
\hline No & \multicolumn{3}{|c|}{ PPT } & Persentase \\
\hline 1 & $\begin{array}{l}\text { PPT RW 01 (PPT } \\
\text { Bougenville) }\end{array}$ & $87 \%$ \\
\hline 2 & $\begin{array}{l}\text { PPT RW 06 (PPT } \\
\text { Dahlia) }\end{array}$ & $89 \%$ \\
\hline \multicolumn{3}{|c|}{ Persentase Rata-rata } & $88 \%$ \\
\hline
\end{tabular}

3. Bantal Cerita Bergambar

Tabel 12. Persentase Rata-Rata Bantal Cerita Bergambar

\begin{tabular}{|c|lll|c|}
\hline No & \multicolumn{3}{|c|}{ PPT } & Persentase \\
\hline 1 & $\begin{array}{l}\text { PPT RW 01 } \\
\text { Bougenville) }\end{array}$ & (PPT \\
\hline 2 & $\begin{array}{l}\text { PPT RW 06 (PPT } \\
\text { Dahlia) }\end{array}$ & $86 \%$ \\
\hline \multicolumn{3}{|c|}{ Persentase Rata-rata } & $85,5 \%$ \\
\hline
\end{tabular}

4. Tablet Permainan

Tabel 13. Persentase Rata-Rata Tablet Permainan

\begin{tabular}{|c|llc|c|}
\hline No & \multicolumn{3}{|c|}{ PPT } & Persentase \\
\hline 1 & $\begin{array}{l}\text { PPT RW 01 (PPT } \\
\text { Bougenville) }\end{array}$ & $87 \%$ \\
\hline 2 & $\begin{array}{l}\text { PPT RW 06 (PPT } \\
\text { Dahlia) }\end{array}$ & $86 \%$ \\
\hline \multicolumn{3}{|l|}{ Persentase Rata-rata } & $86,5 \%$ \\
\hline
\end{tabular}

\section{Pembahasan}

Setelah dilakukan beberapa tahapan maka didapat pembahasan seperti berikut.

1. Tahap perencanaan

Pada tahap ini semua program sudah terlaksana. Program tersebut antara lain : merumuskan tujuan dan tema kegiatan, menganalisis karakteristik anak, merumuskan strategi pembelajaran, 
merancang kebutuhan sumber belajar, merancang media pembelajaran edukatif.

2. Tahap pelaksanaan atau tahap pengembangan Beberapa kegiatan pada tahap ini juga terlaksana dengan baik.

3. Tahap Penilaian

Dari hasil penilaian maka diperoleh :

a. Balok Ceria

Persentase rata-rata yang diperoleh peserta didik dari kedua subyek yaitu PPT Bougenville dan PPT Dahlia dalam menggunakan media Balok Ceria sebesar 87,5\%. Angka tersebut menandakan bahwa media pembelajaran Balok Ceria dapat digunakan dengan baik.

b. Panggung Cerita

Pada media ini, persentase rata-rata yang diperoleh peserta didik dari kedua subyek yaitu PPT Bougenville dan PPT Dahlia dalam menggunakan media Panggung Cerita sebesar $88 \%$. Besaran tersebut menandakan bahwa media pembelajaran Panggung Cerita dapat digunakan dengan baik.

c. Bantal Cerita Bergambar

Untuk media Bantal Cerita Bergambar persentase rata-rata yang diperoleh peserta didik dari kedua subyek dalam menggunakan media Bantal Cerita Bergambar sebesar 85,5\%. Angka tersebut menandakan bahwa media pembelajaran Bantal Cerita Bergambar dapat digunakan dengan baik.

d. Tablet Permainan

Media Tablet Permainan ini memperoleh persentase $86,5 \%$. Angka tersebut menandakan bahwa media pembelajaran Tablet Permainan dapat digunakan dengan baik.

\section{E. KESIMPULAN}

Kesimpulan yang dapat sebagai berikut :

1. Media yang dirancang dan dibuat telah memenuhi standarisasi sesuai usia anak usia dini

2. Media yang dirancang juga diharapkan memenuhi kebutuhan anak usia dini sebagai pengembang motorik kasar dan motorik halus

3. Kegiatan sosialisasi dan workshop bagi
Bunda PAUD mendapat apresiasi yang sangat tinggi. Hal itu terbukti bahwa ketika kami mengadakan kegiatan sosialisasi dan workshop bagi kedua subyek PPT (PPT RW 01 (PPT Bougenville) dan PPT RW 01 (PPT Dahlia)), Bunda PAUD dari PPT lain di kelurahan Balas Klumprik juga datang walaupun mereka tidak termasuk subyek kami.

4. Jenis media pembelajaran yang dihasilkan adalah sebagai berikut:

a. Media pembelajaran jenis aktif : Balok Ceria dan Panggung Cerita

b. Media Pembelajaran jenis pasif : Bantal Cerita Bergambar dan Tablet Permainan

5. Semua jenis media pembelajaran mendapatkan kriteria layak digunakan dengan baik

\section{F. REFERENSI}

Goleman, D. Haufman, P. Ray, M. 2005, The Creative Spirit, Nyalakan Jiwa Kreatifmu di Sekolah, Tempat Kerja dan Komunitas, Jakarta: MLC.

Johnson, Nelson, 1979. Practical Measurements For Evaluation In Physical Education, Third Edition, Minnesota: Burgess Publishing Company.

Kail, R. Cavanaugh, 2007. Human Development A Life Span View, Fourth Edition, Belmont California: Thompson Wadsworth.

Muhyi, M, 2008, Meningkatkan Kecerdasan Kinestetik Melalui Permainan dengan Media Tali, Gramedia Widia Sarana Indonesia, Jakarta

Mutohir, T.C. dan Maksum, A., 2007. Sport Development Index, Konsep Metodologi dan Aplikasi, Alternatif Baru Mengukur Kemajuan Pembangunan Bidang Olahraga, Jakarta: Bessindo Primalaras.

National Institute of Child Health and Human Development Study of Early Child Care and Youth Development Network, 2003. Frequency and Intensity of Activity of Third Grade Children in Physical Education, Arch Pediatr Adolescent, 157, February, 185190. 
Oxendine J.B, 1984. Psychology of Motor Learning, Second Edition, New Jersey : Prentice Hall, Inc.

Prasnig B, 1997. The Power of Learning Style, Bandung: Kaifa.

Carvahal, M.M. Padez, C.M. Moreira, P.D. Rosado, V.M. 2006. Overweight And Obesity Related To Activities In Portuguese Chidlren, 7-9 Years, European Journal of Public Health, 17 (1), 42-46.

Amstrong, T. 1994. Multiple Intelligences: Seven Ways to Approach Curriculum.

http://www.thomasamstrong.com/articles/7ways.htm. Diunduh 11/19/2013.

Anneahira, 2010. Permainan, http://anneahira.com/permainan/index.htm, diunduh 15/3/2014.

Grow, G. 2008. The Bodily-Kinesthetic Intelligence, $\quad$ http://www.longleaf.net/ grow/7In/ Bodily.html, diunduh 15/3/2014.

Fleming N.D, 1995. I am different; not dumb, Modes of presentation (V.A.R.K.) in the tertiary classroom. http://www.varklearn.com/documents/different-notdumb.pdf. Diunduh, 15/3/2014.

Goleman, D. Haufman, P. Ray, M. 2005, The Creative Spirit, Nyalakan Jiwa Kreatifmu di Sekolah, Tempat Kerja dan Komunitas, Jakarta: MLC. 